\title{
Failing to Professionalise, Struggling to Specialise: The Rise and Fall of Health Promotion as a Putative Specialism in England, 1980-2000
}

\author{
PETER DUNCAN* \\ King's College London, Centre for Public Policy Research, Department of Education and \\ Professional Studies, Franklin-Wilkins Building, Waterloo Road, London SE1 9NH, UK
}

\begin{abstract}
Significant attention has been paid to the history of public health in England during the final part of the twentieth century. Within this, however, the field that came to be known as specialist health promotion (SHP) has been relatively neglected. Between 1980 and 2000 those working in this field, generally known as health promotion specialists (HPSs), enjoyed a relative rise in policy and practice prominence before SHP was effectively abandoned by government and others charged with developing and sustaining public-health structures. This paper seeks to explain why the fall of SHP is important; to move towards explaining its rise and decline; and to argue for greater historical attention to be paid to an important but neglected field within health and health care. Essentially, SHP emerged from a set of loose and contingent practices known as health education. A range of important social, economic, organisational and political influences contributed to the slow construction of a putative specialism in health promotion, accompanied by the desire on the part of some (but not all) HPSs to 'professionalise' their role. Finally the projects of both specialisation and professionalisation failed, again as a result of then prevailing organisational and political influences. The importance of such a failure in a so-called era of public health is discussed. In the light of this, the paper concludes by briefly setting out an agenda for further research related to the history of SHP.
\end{abstract}

Keywords: Health Promotion, Public Health, Professionalisation, Specialisation, Specialism

* Email address for correspondence: peter.duncan@kcl.ac.uk

An earlier and shorter version of this paper was presented at the Twentieth International Union of Health Promotion and Education (IUHPE) World Conference on Health Promotion, Geneva, 11-15 July 2010. I am grateful to participants at the session where the paper was presented for their helpful comments. 


\section{Introduction: Professionalisation, Specialisation and Health Promotion}

The processes of professionalisation and specialisation in health care have long been of interest to both historians and sociologists, among others. ${ }^{1}$ Both can be seen as at least in part about laying claim to, developing and protecting knowledge and expertise that finally allows control over a particular domain. Both are essentially political and social processes, depending on the acceptance or acquiescence of others for success, while also employing 'internal' justifications (for example, the development and elaboration of theory) to vindicate their claims. ${ }^{2}$ Professionalisation seeks to turn an occupation into a profession, with all that this implies in terms of power and autonomy within a given sphere of our social world. ${ }^{3}$ Specialisation within medicine and health care seeks to create specialisms of practice, to 'normalise categories of health and sickness', at least partly in order to allow individuals control and jurisdiction over particular categories. ${ }^{4}$ It seems sensible to propose, at least in some cases, a relationship between processes of professionalisation and specialisation. If a group of individuals collectively seek to professionalise, part of their justification for doing so must lie in the belief that they are specialists in a particular area and so warrant being given control over this domain.

The caveat of 'at least in some cases' is important. Specialisation is clearly a feature within the general profession of medicine. However, those involved in a newly emerging medical specialism would presumably see no need to try and 'professionalise' this, in the sense of turning it into a profession, simply because they were already members of the medical profession. (Although of course they would be interested in describing, developing and otherwise laying claim to what they conceived of as the specialist area.) Equally, however, it is easy to imagine a group of individuals who were engaged in practices that they considered to be specialist, but who were lacking the structures of a profession within which these might be developed. Such a group would presumably want to engage in processes of both specialisation and professionalisation. That is to say, they would wish both to lay claim to an area which they regarded as specialist, and to occupy that area as professionals with rights, responsibilities and privileges they had been instrumental in drawing up. In this sort of case, concerns with demarcation and division, the development of theoretical knowledge and practical expertise, appropriate training and so on would transfer between the projects of specialisation and professionalisation, with one reinforcing the other. For some involved (but not necessarily for all), the projects might become indistinguishable from each other.

\footnotetext{
${ }^{1}$ With regard to specialisation, see for example G. Rosen, The Specialisation of Medicine with Particular Reference to Ophthalmology (New York: Froben Press, 1944) and R. Stevens, Medical Practice in Modern England (New Haven, CT: Yale University Press, 1966). Highly influential theoretical or empirically based discussions on the nature of the profession and professionalisation include, for example, Elliot Friedson, Profession of Medicine: A Study of the Sociology of Applied Knowledge (Chicago, IL: University of Chicago Press, 1988) and H.S. Becker et al., Boys in White: Student Culture in Medical School (New Brunswick, NJ: Transaction Books, 1980).

${ }^{2}$ Friedson, ibid:; George Weisz, 'The Emergence of Medical Specialization in the Nineteenth Century', Bulletin of the History of Medicine, 77 (2003), 536-75.

${ }^{3}$ E. Hoyle, 'Professionalisation and deprofessionalisation in education', in E. Hoyle and J. Megarry (eds), World Yearbook of Education 1980 (London: Kogan Page, 1980).

${ }^{4}$ Vanessa Heggie, 'Specialisation Without the Hospital: The Case of British Sports Medicine', Medical History, 54, 4 (2010), 457-74: 457.
} 
This paper examines such a case, that of specialist health promotion in England during the final years of the twentieth century (roughly between 1980 and 2000). Here, a relatively small group, who eventually came to be known as health promotion specialists, tried to lay particular claim to, and develop theoretical knowledge and practical expertise in, the then-emerging field of 'health promotion'. 5 This field had at least in part grown from that of 'health education', a set of loose and contingent practices broadly centred on the communication of health messages through teaching, propaganda and other means. ${ }^{6}$ After a brief period of relative development, specialist health promotion finally declined and those who were attempting to professionalise it failed in their project. For clarity's sake, I will refer throughout this paper to specialist health promotion (SHP) and health promotion specialists (HPSs), although of course my central purpose here is to examine the difficulties these faced in becoming and being regarded as 'specialists' in any sense at all.

Describing and understanding the failure of SHP is important because the late twentieth century has been characterised as an era in which the ideological development of a 'new' kind of public health (which included health promotion) took place. This development was supposedly quite distinct from the narrow clinical concerns that often seemed to preoccupy medicine and health care for much of the earlier part of that century. ${ }^{7}$ This ideological development is represented in part by a wave of policy documents, especially those coming from the World Health Organisation (WHO). ${ }^{8}$ The development has been characterised as part of a broad recognition that momentous global issues such as inequality and sustainability require radical action, including novel ways of thinking about the problems of health and health care. ${ }^{9}$ Clearly there may often be a gap between ideology and theoretical reconceptualisation on the one hand and policy and practice on the other. Nevertheless, it seems odd that in an era during which the ideology of health promotion developed, SHP in England declined and failed. The mismatch here between ideology and reality is a significant prompt for historical attention and the development of historical understanding.

I argue in this paper that the failure of SHP, both in its claim to specialisation and in the professionalisation project that was developed and supported by some HPSs, was the result of three strongly connected difficulties. First, there was the difficulty of the specialists agreeing what they should be doing and how they should be doing it. Second, there was the difficulty of them finding a place within the National Health Service (NHS) to do their work. Third, there was the difficulty of another, much more powerful group- -medicine and its ancillary of public health medicine - staking claim to the domain. Explaining and analysing these problems in detail starts to tell us much about the possibility or otherwise of reorienting and reshaping health services in the twenty-first century.

\footnotetext{
${ }^{5}$ World Health Organisation (WHO), Ottawa Charter for Health Promotion (Ottawa: WHO, 1986).

${ }^{6}$ Max Blythe, 'A Century of Health Education', Health and Hygiene, 7 (1986), 105-15.

${ }^{7}$ I. Kickbush, 'The Contribution of the World Health Organisation to a New Public Health and Health Promotion', American Journal of Public Health, 93, 3 (2003), 383-8.

${ }^{8}$ See, for example, WHO, Health for All by the Year 2000 (WHO: Geneva, 1977): WHO, Alma Ata Declaration (WHO: Alma Ata, 1978); WHO, Targets for Health for All (Copenhagen: WHO Regional Office for Europe, 1985); WHO, 1986, op. cit. (note 5).

${ }^{9}$ P. Hanlon et al., The Future Public Health (Maidenhead: Open University Press, 2012).
} 


\section{Who Were the Specialists and Where Did They Come From? Health Education and the Origins of Health Promotion, 1963-79}

According to the now moribund association that purported to represent HPSs across the United Kingdom (UK), they were 'the UK's experts in health promotion' ${ }^{10}$ In 1985 there were 518 specialists (or equivalents) working across the four UK nations, rising to 859 by 1988 and roughly 1,000 by the mid-1990s, the great majority of them being employed by the NHS. ${ }^{11,12}$ The story being told here, mainly because of differences in policy and its effects within the four nations, is the English one.

While figures for England alone are difficult to extrapolate, it is reasonable to assume that a large proportion of the roughly 1,000 specialists mentioned as working within the UK by the mid-1990s were doing so in the English context. Exactly who were these 'experts'? Where had they come from? What were they actually doing? In order to address these questions, and to begin to understand the claims and interests of SHP in the final years of the twentieth century, it is necessary to consider some aspects of earlier history.

Health promotion, as a concept and related set of practices, emerged during the late 1970s and early 1980s partly from a relatively lengthy tradition of health information and propaganda, which it is probably best to refer to as health education. ${ }^{13}$ The voluntary Central Council for Health Education (CCHE) had been established in 1927, largely at the instigation of the Society of Medical Officers of Health. Until 1950 the CCHE was formed from, among others, representatives of the Ministries of Health and Education, the professional organisations of Medical Officers of Health and the various associations of local authorities. The council's remit was to provide expert advice and resources in matters of health education. In 1950 it was reconstituted to bring it in line with the provisions of the NHS Act 1946, as its aims were now more closely identified with local authorities who largely had responsibility for this area through their public health departments. Thus their representatives and associations at this point assumed full control of the CCHE. ${ }^{14}$ Despite the council's remit and membership, however, commentators have noted that work in this field both before and after its inception had been sporadic, lacking in a sense of proper strategic planning and largely propagandist in approach. ${ }^{15}$ However, developments in the social and medical sciences in the second half of the century began to alter views about health education, what it might be capable of and what it should be doing.

The 1950s saw the strengthening of the academic field of social psychology, particularly in the United States of America, a field that sought amongst other things to develop more sophisticated understandings of health behaviour, including how it could be

\footnotetext{
${ }^{10}$ Society of Health Education and Health Promotion Specialists (SHEPS), The Promotion of Health in the UK (Glasgow: Society of Health Education and Health Promotion Specialists, 1997), 4.

${ }^{11}$ Don Rawson and Colin Grigg, Purpose and Practice in Health Education; The Summary Report of the SHER Project (London: South Bank Polytechnic, 1988), 31.

12 SHEPS, op. cit. (note 10), 5.

${ }^{13}$ See, for example, Blythe, op. cit., (note 6); and Peter Duncan, 'Dispute, Dissent and the Place of Health Promotion in a Disrupted Tradition of Health Improvement', Public Understanding of Science, 13, 2 (2004), 177-90.

${ }^{14}$ National Archives, Central Council for Health Education: Minutes and Papers. Available online at www. nationalarchives.gov.uk (accessed 2 July 2012).

15 See for example Blythe, op. cit. (note 6); Anne Hardy, Health and Medicine in Britain since 1860 (Basingstoke: Palgrave Macmillan, 2001); and I. Zweiniger-Bargielowska, 'Raising a Nation of Good Animals: The New Health Society and Health Education Campaigns in Interwar Britain', Social History of Medicine, 20, 1 (2007), 73-89.
} 
changed. ${ }^{16}$ During the same decade, the power of the then new medium of television had gradually increased so that, by the 1960 s, it had become a 'key media player' ${ }^{17}$ Relatively sophisticated methods of advertising through this 'new' medium were emerging. The development and shaping of 'consumers' through advertising led social psychologists towards attempting to understand these new methods and their impact on individual behaviour. ${ }^{18}$

At the same time, epidemiology was beginning to connect lifestyle behaviours such as diet and smoking with the onset of morbidity and premature mortality. The establishment of a connection between smoking and lung cancer at the beginning of the 1950s was especially important in drawing attention to the value of efforts aimed at 'lifestyle prevention', although, in the case of smoking, the caution of policymakers in tackling a widespread, culturally embedded behaviour meant that it took some time to establish reasonable 'anti-smoking' programmes. ${ }^{19}$

These developments in the fields of psychology and epidemiology - greater understanding of how people behaved, how they were influenced in their behaviour and how lifestyle was connected to ill health - contributed to the belief that health education could play an increasingly important part in preventing illness and disease as an emerging specialist area. ${ }^{20}$ The Joint Committee of the Central and Scottish Health Services Councils (better known as the Cohen Committee on Health Education) was formed in 1959 to consider how health education could be developed in order to play such a part and in 1963 it produced its report. ${ }^{21}$

Perhaps unsurprisingly, given the 'lifestyle prevention' context within which the Cohen Committee was originally established, the Cohen Report strongly recommended that health education should address issues such as cancer, diet and smoking. ${ }^{22}$ However, it also made recommendations relevant to understanding the development of health education as a putative specialism, two of which are especially important here. In the first place, the report recommended that a 'strong central board' be set up to replace the voluntary CCHE. ${ }^{23}$ This board should co-ordinate activity at a national level and encourage the development of specialist health educators. ${ }^{24}$ Second, it recommended that local authorities should more systematically recruit and train these educators, who were coming increasingly to be known as health education officers (HEOs). ${ }^{25}$

${ }^{16}$ G. M Hochbaum, 'Why People Seek Diagnostic X-rays', Public Health Report, 71, 4 (1956), 377-80.

17 Virginia Berridge and Kelly Loughlin, 'Smoking and the New Health Education in Britain 1950s-1970s', Ameerican Journal of Public Health, 95, 6 (2005), 956-64.

18 Vance Packard, The Hidden Persuaders (London: Darton, Longman and Todd, 1957).

${ }^{19}$ Berridge and Loughlin, op. cit. (note 17).

${ }^{20}$ See P.A. Coventry and J.V. Pickstone, 'From What and Why Did Genetics Emerge as a Medical Specialism in the 1979s in the U.K.?', Social Science and Medicine, 49 (1999), 1227-38, for an analysis of the putative grounds for the development of specialisations within medicine and health care. They draw particular attention to the idea of 'technical innovation' as a spur to specialisation. In some respects at least, the developments that have been described here with regard to health education might be thought of as representing such innovation within this particular field.

${ }^{21}$ Cohen Committee, Health Education: Report of a Joint Committee of the Central and Scottish Health Services Councils (London: Her Majesty's Stationery Office, 1964).

22 This concentration on 'medical' topics is doubtless also related to the fact that, of twelve members sitting on the Cohen Committee, seven were doctors.

${ }^{23}$ Cohen Committee, op. cit. (note 21), 6.

24 Cohen Committee, op. cit. (note 21), 187-93.

25 Cohen Committee, op. cit. (note 21), 197 and 215. 
Cohen's 'strong central board' was finally established in 1968 as the Health Education Council (HEC). Its formation - and indeed most of its working life - was difficult, as were the lives of its successor organisations. This was at least in part due to tensions over who should control the work of this body, which was attempting at the national level to co-ordinate and develop the embryonic specialism of health education. Should it simply be an adjunct to medicine or should it be allowed somehow to develop at arm's length from medical influence ${ }^{26}$ The problematic question of medicine's influence over those working in the fields of health education and health promotion extends throughout the history being considered.

The task of developing and embedding HEOs in local authority structures was possibly even more difficult than the creation of the HEC. ${ }^{27}$ In 1968, five years after the publication of the Cohen Report, one medical officer of health (MOH) reported that it was generally unclear how many HEOs were actually employed by local authorities, what qualifications they possessed and what their background experience was. ${ }^{28}$

A small number of secondary sources start to cast some light on the identity and practices of HEOs working in local authorities during the late 1960s and early 1970s. In 1972 a survey was undertaken by Keith Tones, an academic who in 1974 would establish one of the first postgraduate diploma courses in health education (at Leeds Polytechnic), and who would become one of the key drivers of the 'theorising' component within attempts to develop the putative specialism of health education in the decade or so following. Tones reported that over half the HEOs then in post in England, Wales and Northern Ireland (just under 200) had 'migrated' to the occupation from nursing. The remainder had come from teaching, dietetics, administration or another local authority public health-related role. In addition to his own survey work, Tones, using data derived from the HEC, identified that, while HEOs were based in 'units' within local authorities (of which at that point there were forty), about fifty per cent of these units comprised just one person. As to what HEOs actually did, Tones described their involvement in programme planning, public relations, policy making, teaching, lecturing and routine administration. ${ }^{29}$

This picture of HEOs as involved in a range of diverse practices is supported by the single published account of life as a HEO in the late 1960s and early 1970s that I have been able to identify. Linda Ewles worked during this period for Bristol City Council Public Health Department:

I cut my health education teeth working on campaigns...such as one for the new measles immunisation. . exhibitions such as an annual three-day event at the local flower show where we promoted topics such as accident prevention and demonstrated 'the kiss of life'; running stop-smoking and slimming groups (as we called them then); and giving talks on nutrition, accident prevention and first aid to groups such as Mothers' Unions and the Brownies. And, of course, there was the audio-visual aid loan service of films, slides and film-strips, and the inevitable posters and leaflets. Activities requiring more skills

\footnotetext{
${ }^{26}$ Ian Sutherland, Health Education: Half a Policy (Cambridge: National Extension College, 1987), 41. As Sutherland notes, a 'medical shadow' was cast over the HEC from its beginning by, among other things, the establishment of a 'Medical Research Division' within the Council.

27 Ibid.

${ }^{28}$ R.C. Wofinden, 'Education and Training of Health Education Officers', Public Health, 82, 3 (1968), $138-42$.

${ }^{29}$ B.K. Tones, 'The Role of the HEO: A Study of Emergent Professionalism' (unpublished MSc dissertation: Leeds Polytechnic, 1974), 44. The survey is rather confused by the fact that, while most of its respondents were actually HEOs, others such as health visitors or nursing officers were reported as having responsibility for health education within their particular organisations. Tones described this state of affairs as "symptomatic of role diffusion and uncertainty'.
} 
and experience, such as working with the LEA [local education authority] on devising a health education syllabus for local schools, and in-service training for teachers and health visitors, were mainly undertaken by my senior HEO colleagues.... ${ }^{30}$

Ewles' picture of a loose set of activities and practices (from running exhibitions at flower shows to planning a school's health education syllabus) is made more vivid by the fact that she does not explain how they were decided on. They do not appear to have been based on particular normative conceptions of what a HEO should be doing, or any established views of priority. In this sense, as is the case with Tones' survey account, the practices seem not only to be diverse but also contingent.

Yet at almost exactly the same time that Linda Ewles was involved as a Health Education Officer in giving talks to local societies and lending film material, a striking global agenda for health improvement was emerging, which would ultimately affect the work of HEOs such as Ewles. Its initial impetus was the Lalonde Report, produced under the direction of the Canadian Minister of Health, Marc Lalonde. As a politician, he was faced with the realisation that, despite the ever-increasing capacity of medical services to deal with illness and disease, these alone could now not offer the dramatic improvements in health required by advanced societies. ${ }^{31}$ The Lalonde Report was important not least because it emphasised the crucial place of social structures in determining and dealing with problems of ill health. To this extent, it opened up the possibilities of action for health improvement well beyond the 'lifestyle prevention' activities and practices described by Tones and Ewles in the early 1970s. The Lalonde Report was quickly followed by a string of declarations from the WHO. ${ }^{32}$ These sought to establish the philosophical and practical basis of what was now being talked about as 'health promotion', defined a short time later by one theorist as 'the process of enabling individuals and communities to increase control over the determinants of health and thereby improve their health'. 33

As well as forming the basis of 'health promotion', the focus on the wider, structural determinants of health inspired by Lalonde also prompted some to alter their conceptions about the nature of public health. The post-war period had seen 'public health' as being largely constituted by concerns to do with the narrow mapping of disease and the planning of treatment services. ${ }^{34}$ Now, for some, the idea of the so-called new public health began to emerge. ${ }^{35}$ As with health promotion, the 'new public health' was largely defined by its altered focus on the structures creating health or causing illness. ${ }^{36}$ To this extent, it often seems hard to split a hair between 'health promotion' and 'new' conceptions of public health, a point that will become significant in explaining the failure of SHP both properly to become a specialism and to professionalise.

The expansive and possibly idealistic international agenda that I have described, and which gave rise both to health promotion and the new public health, was being developed

\footnotetext{
${ }^{30}$ Linda Ewles, 'Paddling Upstream for 50 years: The Role of Health Education Officers', Health Education Journal, 52, 3 (1993), 172-181: 174.

${ }^{31}$ Marc Lalonde, A New Perspective on the Health of Canadians (Ottawa: Ministry of Supply and Services, 1974).

32 WHO, 1977, 1978, 1985, 1986, op. cit. (note 8).

33 Don Nutbeam, 'Health promotion glossary', Health Promotion, 1, 1 (1986), 113-127: 114.

${ }^{34}$ V. Berridge et al. (eds), Public Health in the 1980s and 1990s: Decline and Rise (London: Wellcome Trust Centre for the History of Medicine, 2006).

35 Duncan, op. cit. (note 13).

36 John Ashton and Howard Seymour, 'An Approach to Health Promotion in One Region', Community Medicine, 7 (1985), 78-86.
} 
at almost exactly the same time that in England HEOs were facing reorganisation. They were being forced to move from their local authority bases into the National Health Service (NHS) under the terms of the 1974 NHS reorganisation. They were not alone in this, being accompanied by their $\mathrm{MOH}$ bosses and the much-diminished community health empire over which MOHs had responsibility. (This also included community midwifery and health visiting services.) The NHS reorganisation that took HEOs into the Health Service followed the reshaping of local authority welfare and social work services in the wake of the 1968 Seebohm Report. ${ }^{37}$

MOHs (renamed specialists in community medicine), HEOs and their former local authority community health colleagues now found themselves in a service dominated by, and essentially only interested in, imperatives related to acute treatment and care. The morale of community health personnel was significantly affected. ${ }^{38}$ Commentators have noted that the effects of the 1974 reorganisation on UK health services and on the broad health policy agenda have been relatively under-researched. ${ }^{39}$ What is clear, however, is that the influence of MOHs on local community health was weakened. This was partly because of the rather nebulous role they assumed now that they were within the NHS, which was mainly to do with preventing and dealing with communicable and infectious diseases. ${ }^{40}$ It was also because, in moving to the Health Service, MOHs lost their longstanding immediate organisational relationship with Environmental Health Officers who, after some policy vacillation, remained in local authorities. ${ }^{41}$

The public health agenda after 1974 was consequently diffused, largely as a result of the fracturing of the public health work force that I have described. Some local authorities maintained an interest in health education and the emerging idea of health promotion, although this was often difficult, given organisational barriers. ${ }^{42}$ HEOs struggled to maintain role and identity, as well as relationships with traditional allies such as health visitors who, while also now in the NHS, were located in a different organisational tier. (HEOs worked at area level, while health visitors were part of the district work force.) The impact of the 1974 reforms generally on local public health is complex but it certainly involved severed ties, disrupted relationships and still further re-balancing of the political economy of health in favour of treatment and care. ${ }^{43-45}$

Nationally, a government consultative document on prevention was published in 1976, shortly after the reorganisation that had adversely affected local health education and public health services to such a significant extent. ${ }^{46}$ 'Prevention and Health' was firmly rooted in the idea of individual responsibility for disease prevention. It suffered significant criticism for failing to acknowledge wider structural influences on health and neglecting the gathering international agenda that emphasised the importance of dealing with

${ }^{37}$ Charles Webster, The National Health Service: A Political History (Oxford: Oxford University Press, 2002).

38 Berridge et al., op. cit. (note 34).

${ }^{39}$ Coventry and Pickstone, op. cit. (note 20).

${ }^{40}$ Berridge et al., op. cit. (note 34$)$.

41 Webster, op. cit. (note 37), 104.

42 Ged Moran, 'Health Promotion in Local Government: A British Experience', Health Promotion, 1, 2 (1986), 191-200.

43 Berridge et al., op. cit. (note 34).

${ }^{44}$ Ewles, op. cit. (note 30).

45 Jane Lewis, What Price Community Medicine: The Philosophy, Practice and Politics of Public Health since 1919 (Brighton: Wheatsheaf, 1986).

46 Department of Health and Social Security (DHSS), Prevention and Health: Everybody's Business (London: Her Majesty's Stationery Office, 1976). A White Paper was published in the following year. 
structures in order to improve health. ${ }^{47}$ The contrast between UK government thinking about prevention on the one hand and global conceptions of 'health promotion' on the other was marked. There were sporadic challenges to the narrowing and 'medicalisation' of public health that had occurred following the 1974 reorganisation. However, such challenges were marginal and lacking in effect. ${ }^{48}$ Attempts at directing attention towards the impact of economic and social structures on health were actively thwarted by the Conservative government that was elected in 1979, one of the best known examples being suppression of the 1980 Black Report on inequalities in health. ${ }^{49}$ The suppression was deeply disappointing to many but it was hardly surprising given the incoming government's unilateral abandonment of the post-war economic and social welfare consensus. ${ }^{50}$

\section{Disease Prevention and Radical Activism: Health Promotion and the Progress of Specialisation in the 1980s}

Despite the organisational difficulties and conceptual tensions that I have described, the early 1980s saw some efforts towards providing greater shape to the work of HEOs. Policy and other initiatives attempted to move them from the kind of embroilment in loosely or perhaps even unconnected practices described by Linda Ewles and towards more careful description of their domain, their putative expertise and the systematic application of this in practice. One of these was the so-called Kirby Report on the training and development of health education officers. ${ }^{51}$ Kirby had started off by reviewing the grading, pay and conditions of clerical and administrative staff in the NHS. Almost by accident, this review had uncovered HEOs among the labyrinthine administrative grading systems of the Health Service. Recognising HEOs appeared to be doing quite different work from other administratively graded staff, the review sought to consider and report on this group separately. ${ }^{52}$

For the first time, Kirby identified common job descriptions for HEOs that could be applied across health authorities, emphasising the health education programme planning, co-ordination, training and expert advice role of the officers. ${ }^{53}$ The report also established the nature of an induction programme for those who were in the early stages of their careers as HEOs. Moreover, it provided official acceptance of the postgraduate diploma in health education (which by now had been taught in Leeds Polytechnic and a small number of other higher education institutions for several years) as the basic professional qualification for HEOs. The government commended the Kirby Report, but did little with it. ${ }^{54}$ However, it had at least provided a degree of tightness to the HEO role. In effect,

${ }^{47}$ D. Haran, 'NHS: Prevention or Cure?', Radical Statistics Newsletter, 10 (1976), 6-8.

${ }^{48}$ See, for example, Unit for the study of health policy, Rethinking Community Medicine: Towards a Renaissance in Public Health (London: Department of Community Medicine, Guy's Hospital Medical School, 1979).

${ }^{49}$ P. Townsend et al., Inequalities in Health (London: Penguin, 1988). For a chronological account of the suppression of the Black Report, see the introduction to this volume. For further interpretations of the suppression's source and motivations, see Virginia Berridge and Stuart Blume (eds), Poor Health: Social Inequality before and after The Black Report (London: Frank Cass, 2003).

${ }^{50}$ N. Timmins, The Five Giants: A Biography of the Welfare State (London: Fontana Press, 1996).

${ }^{51}$ National Health Service (NHS), Recruitment, Training and Development of HEOs: A Report for the National Staff Committee, Administrative and Clerical Staff (London: NHS, 1981).

52 Ewles, op. cit. (note 30).

53 NHS, op. cit. (note 51).

${ }^{54}$ Ewles, op. cit. (note 30). 
the role having been tightened, there was now the possibility of considering more exactly what kind of specialist knowledge and theory it might require.

Attempts to develop health education and health promotion theory constituted a further effort to better define and describe the putative specialism in which HEOs were working. George Weisz argues that a 'community of scholars addressing a research problem' is a condition for the development of specialism in the medical field. ${ }^{55}$ In England, a small and scattered community of scholars addressing the problem of the theoretical foundations of health education and health promotion emerged through their association with the founding of postgraduate courses related to the field. The first course was begun at Leeds Polytechnic in 1974, followed shortly afterwards by further courses at Bristol and South Bank Polytechnics and Chelsea College London. ${ }^{56}$ The research problem faced by this small band of scholars was to describe health education and the emerging idea of health promotion carefully, draw the two together, make clear exactly where their theoretical roots lay or might be developed, and make a case for how this theory might support practice. $^{57}$

It was a difficult problem, partly because the separate histories of health education and health promotion (and the quite different contexts in which ideas relating to them had developed) gave rise to a range of conceptions about what they actually were and what they should be trying to do. These included at one extreme the kind of individualistic approach represented by 'Prevention and Health' and at the other the emphasis on structural change of Lalonde and the WHO. Some saw the research problem as partly involving an attempt at reconciliation, trying to convince health promoters (as those working in the field were now being increasingly called) that these and other approaches were equally valid. ${ }^{58}$ Others saw theorising as at least to some degree about making explicit the values underlying the separate approaches or even possibly asserting that one particular approach was better than the rest. ${ }^{59,60}$ The different conceptions of health promotion that emerged from this early theorising contributed to later rifts between those working in SHP and, ultimately, as I will argue, to the failure of specialisation and professionalsation.

The early 1980s also saw a more careful, or at least clearer, description of the health promotion domain through the emergence, in the English context, of work related to the global WHO agenda. From its declarations, a number of significant figures within WHO, including the sociologist Ilona Kickbusch (unusual for being both a woman and a prominent figure in global public health), renewed the idea that local authorities should have a central role in promoting the health of their communities, an idea that gradually turned into the 'Healthy Cities' movement. ${ }^{61}$ The idea was taken up enthusiastically in some areas of England (as well as other parts of the UK), notably Liverpool, a declining port city with significant social problems. John Ashton, a specialist in community medicine and an advocate of the 'new' public health, appointed Howard Seymour as a

55 Weisz, op. cit. (note 2), 539.

56 Rawson and Grigg, op. cit. (note 11).

57 Andrew Tannahill, 'What is Health Promotion?', Health Education Journal, 44, 4 (1985), 167-8.

58 Andrew Tannahill, 'Regional Health Promotion Planning and Monitoring', Health Education Journal, 46, 3 (1987), 125-7.

59 Alan Beattie, 'Health Education and the Science Teacher: Invitation to a Debate', Education and Health (1984), 9-16.

${ }^{60}$ Keith Tones, 'Education and Health Promotion: New Direction', Journal of the Institute of Health Education, 21, 4 (1983), 121-31.

61 WHO, Twenty Steps for Developing a Healthy Cities Project, second edn (Copenhagen: WHO Regional Office for Europe, 1995). 
health promotion specialist. Both were employed by the NHS but worked to draw together the Health Service and Liverpool City Council in a programme of work aimed at creating 'The Healthy City'. ${ }^{62}$ The same kind of process took place in other areas and represented one way in which practitioners tried to overcome the fractures and divisions that had been caused by the 1974 reforms; and to challenge, at least implicitly, the ideology of the libertarian Conservative government.

Despite all this, however, numbers of HEOs (or HPSs, as some started to call themselves during this period of theoretical and practical development in health promotion) remained low. However, a further and tragic development during this period provided the opportunity to expand the numbers of specialist staff. This was the advent of the HIV/AIDS pandemic.

The pandemic, according to one historian, offered public health and its " "policy tool kit" of epidemiology and health education [the chance] to define the parameters of policymaking' in a way unique in post- war British public health history. ${ }^{63}$ HIV/AIDS could not yet be treated and its potential for catastrophic spread was deeply alarming. While programmes of research into causation developed, and thus whatever potential might exist for treatment was discovered, prevention was essentially the only strategy open to policy makers. ${ }^{64}$ Realisation of this led to relatively large amounts of money going to health authorities for HIV/AIDS prevention work. Some of this found its way to health education and health promotion services. Rawson and Grigg, in the only extensive study actually undertaken during this period of the development of specialist health education (as these authors were still referring to it) report a significant rise in HEO posts. In England, Wales and Northern Ireland the number of posts increased by over fifty per cent from 518 in 1985 to more than 850 in $1987 .{ }^{65}$ Another analysis, conducted for the Health Education Authority (which had replaced the HEC in 1987), suggested that a quarter of these new posts were related to HIV/AIDS and were fixed-term contracts connected to year-on-year ring-fenced HIV prevention monies. ${ }^{66}$

This suggests that the expansion of services came out of political necessity and shortterm expediency rather than careful planning and development of the putative specialism. Moreover, some commentators have seen the focus on 'topics' like HIV (along with others such as illicit drugs and alcohol) as driven by medicine and a relatively narrow conception of health; as 'atomising' health behaviour and thus limiting or even dismissing attention towards the social context on which health promotion (or at least the version inspired by Lalonde and promoted by the Ottawa Charter) was supposed to be based. ${ }^{67} \mathrm{~A}$ sense emerges of practice being disputed, dichotomised and not necessarily grounded in coherent thoughts about what health promotion, if it was indeed a specialist field, should be doing.

Yet in other ways the advent of HIV suited the aspirations and interests of some involved in health promotion very well. In the early stages of the pandemic, one important kind of response to it was through grassroots activism. ${ }^{68}$ This connected neatly with the

${ }^{62}$ Ashton and Seymour, op. cit. (note 36).

63 Virginia Berridge, AIDS in the UK: The Making of Policy (Oxford: Oxford University Press, 1996), 9.

64 Ibid.

65 Rawson and Grigg, op. cit. (note 11), 21.

${ }^{66}$ Y. Keeley-Robinson, Health Education/Promotion in the NHS post-Griffiths (London: Health Education Authority, 1987).

${ }^{67}$ D. Lupton, The Imperative of Health (London: SAGE, 1995), 88.

68 Berridge, op. cit. (note 63). 
radical tendencies of some people involved in SHP, which perhaps for those individuals was an almost necessary consequence of doing work that was at the margins of health policy. ${ }^{69}$ The 1980s saw the development of radical activism in health education and health promotion through, for example, groups such as the Feminist Health Education Officers Group (founded in 1980) and the Radical Health Promotion Collective (1985). These groups organised meetings and fringe conferences. They produced journals and other publications with an almost samizdat flavour. ${ }^{70}$ The radical voice also appeared in research and other activity that was funded or sponsored by the medical or other mainstream. ${ }^{71}$ While these were often small-scale activities, they had a relatively wide impact in terms of shaping the work philosophies of health education officers. Rawson and Grigg, for example, report a strong preference on the part of HEOs for moving away from addressing questions of individual behaviour change and towards the structural issues that formed the basis of the global rhetoric on health promotion. ${ }^{72}$

So was a consensus emerging in the mid-1980s about what HPSs should be doing, and if this was the case does it suggest that a coherent specialism was beginning to emerge? I argue against this idea. The radical activists and those sympathetic to a radical agenda were mainly working in the highly structured and largely medically focussed NHS. The capacity that they had to enact a radical agenda was virtually non-existent and their organisational power base extremely limited. ${ }^{73}$ At the same time as the radical agenda was being cherished and sympathised with, others considered that the best route to more power lay in attempts to professionalise SHP; to develop the kinds of structures that would give it greater autonomy and control over its affairs. The question as to whether this 'professionalisation project' was a reasonable one in the context of the dispute that I have described about what SHP should be doing, together with the ambiguity that existed in its associated practices, is an important one that I will return to in later discussion.

The general acceptance by the Kirby Report that HEOs should undergo postgraduate training had provided an impetus for the association that represented some of them - known by the mid-1980s as the Society of Health Education and Health Promotion Officers - to develop plans for a national training scheme. ${ }^{74}$ At about the same time, a code of conduct for HPSs was being formulated, as well as plans for a national register of specialists. ${ }^{75,76}$ The society was thus attempting to drive, almost entirely alone, the implementation of the three key descriptive elements associated with an occupation becoming a profession: statutory training, registration and regulation. ${ }^{77}$

There was significant dissent from this professionalisation project, mostly from the radical activists. They saw professionalisation as no more than an attempt to mimic

\footnotetext{
${ }^{69}$ David Evans and Teri Knight, There was no Plan: The Origins and Development of Multidisciplinary Public Health in the UK (Bristol: University of the West of England, 2006).

${ }^{70}$ For example, the journal Radical Health Promotion.

${ }^{71}$ See, for example, W. Farrant and J. Russell, The Politics of Health Information: 'Beating Heart Disease' as a Case Study of Health Education Council Publications (London: Institute of Education, 1986).

72 Rawson and Grigg, op. cit. (note 11), 134.

73 Rawson and Grigg, op. cit. (note 11), 136.

74 Society of Health Education and Health Promotion Officers, The Education and Training of Health Education and Health Promotion Officers: A Proposal for a National Training Scheme (Warwick: Society of Health Education and Health Promotion Officers, 1989).

75 Society of Health Education Officers, Code of Conduct (Carlisle: Society of Health Education Officers, 1985).

76 Society of Health Education and Health Promotion Officers, op. cit. (note 74).

${ }^{77}$ Hoyle, op. cit. (note 3).
} 
medicine's structures of power and control. ${ }^{78}$ Set against this was the professionalisers' beliefs that shifts within the NHS towards a more directive system of general management, recommended by the 1983 Griffiths Report, made it even more important that HPSs should try to gain greater control over their work through professionalisation. ${ }^{79,80}$

\section{The Hopeless Pursuit of Professionalisation: Multidisciplinary Public Health and the Decline of Specialist Health Promotion in the 1990s}

In fact, Griffiths turned out to be just a provisional test for HPSs. Further organisational reform of the NHS in the late 1980s and early 1990s presented them with much more dramatic problems. The introduction of the so-called internal market within the Health Service, dividing the NHS into a system of 'purchasers' and 'providers', had an extremely negative effect on SHP. ${ }^{81}$ HPSs awkwardly straddled the purchaser-provider divide that was the central feature of the new internal market. Some of what HPSs did could be understood as 'purchasing' activity; for example, identifying areas of health promotion need and planning responses to this. Some of it, however, was clearly 'provider' work; for example, organising health awareness campaigns or training on health issues. So should HPSs become 'purchasers' or 'providers'?

District health authorities (the location of most HPSs prior to the internal market reforms) made some attempt to address this fundamental problem of organisational location, although it was seldom a priority. ${ }^{82}$ Some placed health promotion departments within provider units (most by now becoming NHS Trusts); others put them as purchasers within their own planning and public health functions. A further organisational arrangement was the allocation of some staff within a department to purchaser and others to provider. The Health Education Authority analysed organisational options and tried to make national recommendations as to what might work best. ${ }^{83}$ However, regardless of whether departments were literally divided or not, the general effect was for the planningprovision continuum in SHP to be broken. The organisation representing some HPSs, now known as the Society of Health Education and Health Promotion Specialists (SHEPS), reported multiple tales of service fragmentation and dislocation. ${ }^{84}$

Ironically, the reforms that fragmented specialist health promotion were followed by the Conservative government's first public-health strategy, the first attempt at national strategy in this area since 'Prevention and Health' back in 1976. ${ }^{85}$ This strategy, entitled 'The Health of the Nation', can in some ways be interpreted as a health promotion strategy, or at least as a strategy for a particular kind of health promotion based on principles of individual responsibility and lifestyle change. Despite ideological opposition to this sort

\footnotetext{
${ }^{78}$ M. Black, 'Issues surrounding community participation', in Health; The Community's Wealth, Report of the Proceedings of the Health Education and Health Promotion Specialist Seminar, Belfast, 3-7 April (Carlisle: Society of Health Education and Health Promotion Officers, 1989); S. Chand et al., Association of HEOs: Recruitment and Employment (London: Association of HEOs, 1989).

${ }^{79}$ Roy Griffiths, NHS Management Inquiry (London: Department of Health and Social Security, 1983).

${ }^{80}$ Society of Health Education and Health Promotion Officers, op. cit. (note 74).

81 The idea of the internal market was heralded in Secretaries of State, Working for Patients. Cm.555 (London: Her Majesty's Stationery Office, 1989).

${ }^{82}$ Ewles, op. cit. (note 30).

83 Doug Smith, Options for the Future: Organisational Arrangements for Health Promotion Services (London: Health Education Authority, 1993).

${ }^{84}$ Lee Adams, Health Promotion at the Crossroads (Sheffield: Society of Health Education and Health Promotion Specialists, 1993).

${ }^{85}$ Secretary of State for Health, The Health of the Nation (London: Her Majesty's Stationery Office, 1992).
} 
of approach on the part of some HPSs, others welcomed 'The Heath of the Nation' because at least now government policy was actively talking about health improvement rather than just disease treatment or service organisation. ${ }^{86}$

The strategy also provided a boost for Directors of Public Health (DPH). The DPH role had been created as part of an attempt to re-invigorate public health medicine, which many saw as having lost its way since the 1974 reforms, the loss of the $\mathrm{MOH}$ and the arrival of the Specialist in Community Medicine. ${ }^{87}$ 'The Health of the Nation' added to this impetus by giving DPHs new responsibilities for such things as partnership working for health improvement between local and health authorities.

As part of its renaissance, public health medicine had also quite cleverly capitalised on the international WHO agenda. It was often now called simply 'public health' rather than 'public health medicine', a renaming that at least sometimes made easier an elision to the 'new public health', with its focus - much like health promotion, as I have argued - on structures and environment. ${ }^{88}$ There was still a firm belief that medics (public health doctors) should be leading public health work. However, there were also vague rhetorical commitments to the idea of public health as a multidisciplinary enterprise, a nod to the implications of the renaming that was taking place. These turned out to be enough to kick-start a movement that became known as multidisciplinary public health (MDPH). ${ }^{89}$

The contrast from this point on between the SHP struggle to professionalise on the one hand, and the confident emergence of MDPH on the other, is striking. Consider SHP in the first place. The register of HPSs that was supposed to form one of the cornerstones of professionalisation was finally published in 1991. However, it stood alone: statutory training and registration remained as distant as ever. ${ }^{90}$ At the same time, those activists who were opposed to professionalisation continued in their efforts to represent health promotion in radical terms, as the antithesis of the power and control over a domain that was seemingly sought by SHEPS. Yet there was also a sense on the activists' part that their 'radical' vision of health promotion had not moved forward much, at least partly because Conservative government policy had comprehensively thwarted genuinely radical direction. ${ }^{91}$ As a commentator at one activist event, a symposium on health promotion theory involving practitioners and academics, noted:

Once the symposium got underway it soon became apparent that the key aim, as far as a significant number of the participants were concerned, was to find a way of regrouping in the face of hostile day-to-day working conditions.... The key dilemma which then quickly surfaced and hovered throughout... debates was: 'How, if at all, can health promotion specialists employed by the state put their radical principles into practice?' Or, as one participant succinctly put it: 'How can we hang on to "Health for All" when faced with "Health of the Nation", 92

\footnotetext{
${ }^{86}$ Ewles, op. cit. (note 30).

${ }^{87}$ Donald Acheson, Public Health in England: The Report of the Committee of Inquiry into the Future Development of the Public Health Function (London: Her Majesty's Stationery Office, 1988); V. Berridge et al., op. cit. (note 34).

${ }^{88}$ Berridge et al, op. cit. (note 34).

${ }^{89}$ Berridge et al, op. cit. (note 34).

${ }^{90}$ Society of Health Education and Health Promotion Specialists, Register of Health Education and Health Promotion Specialists (Birmingham: Society of Health Education and Health Promotion Specialists, 1991).

${ }^{91}$ Lee Adams and Ewan Armstrong, 'Penrith Paradoxes: From Analysis to Synthesis II: The Revenge', Health Care Analysis, 4, 2 (1996), 112-19.

92 Peggy Foster, 'Is There a Future for Radical Health Promotion?', Health Care Analysis, 4, 2 (1996), 120-6:10.
} 
On a day-to-day basis, many HPSs had to find ways of working with the individual lifestyle agenda central to government strategy in the area, even if they were privately distasteful of it. This was not least because it was increasingly embedded in approaches to practice. ${ }^{93,94}$ Dispute about the nature and purpose of health promotion continued. Doubt about what should be done, how and why persisted. Specialisation in the broad field of medicine, as I have claimed, seeks in part to 'normalise categories of health' in order to allow those with claims over the area concerned to gain control and jurisdiction. ${ }^{95}$ The circumstances of SHP in the mid-1990s give little impression of a 'normalised category'. If normalisation is part of the ambition of those who are attempting to specialise, and if such a goal is so deeply elusive as it seems to have been in the case of SHP, it is unlikely that processes of professionalisation (seeking and being granted power over the field concerned) will be accepted by those who are able to grant that power. It is perhaps then hardly a surprise that the Department of Health made clear in 1996 it could not support the attempts being made by SHEPS to move SHP towards becoming a profession. This lack of official sanction led the society almost immediately to suspend efforts to gain mandatory status for its registration scheme. ${ }^{96}$ The suspension, as it happened, turned out to be abandonment.

I now want to move back to MDPH and claim again the starkness of the contrast between its gathering pace during this period and what happened to SHP. Informal networks within the non-medical public health field finally led in 1997 to 'statements of intent' between the embryonic MDPH Forum, the Royal Institute of Public Health and the Faculty of Public Health (FPH) with regard to the development of multidisciplinary public health education and accreditation. ${ }^{97}$ The faculty, the medically organised 'gatekeeper' to the public health profession, opened its part 1 examinations to non-medics in 1998. The scene was set for liberalisation of the public health workforce, potentially at all levels; up to this point, at least in terms of the most influential positions, it had been completely the preserve of medicine. It is hard to avoid the conclusion, when comparing these relatively rapid and positive developments in MDPH with what was happening at the same time in SHP, that, for at least some HPSs, moving into the arena of so-called multidisciplinary public health as reconstituted public health specialists, away from the disputes and doubts of specialist health promotion, must have seemed very attractive. ${ }^{98}$

The 'New' Labour government, elected in May 1997, published its first public health strategy almost two years after the FPH opened up its part 1 exams to non-medically qualified candidates. ${ }^{99}$ The 'Saving Lives' strategy contained no reference to health promotion, either as a broad field or as a specialism. It had been quietly dropped from policy. The health challenges of the new century were to be met by a rather vaguely described 'multidisciplinary public health workforce'. ${ }^{100}$ Of course, this would include some whose background was in SHP. However, the crucial point is that SHP itself was

\footnotetext{
93 Health Education Authority, Helping People Change: Training Course for Primary Health Care Professionals (Oxford: Health Education Authority National Unit for Health Promotion in Primary Care, 1993).

94 Knowledge House, Better Living, Better Life (Maidenhead: Knowledge House, 1993).

95 Heggie, op. cit. (note 4).

96 Society of Health Education and Health Promotion Specialists, 'Mandatory Registration on Hold', Society of Health Education and Health Promotion Specialists News (July 1996), 1.

97 Evans and Knight, op. cit. (note 69), 1.

98 Evans and Knight, op. cit. (note 69).

99 Secretary of State for Health, Saving Lives: Our Healthier Nation (London: The Stationery Office, 1999).

${ }^{100}$ Department of Health, Health Service Circular: Saving Lives: Our Health Nation White Paper and Reducing Health Inequalities: An Action Report (London: Department of Health, 1999), 4.
} 
not preserved. The HPS workforce was diffused and dispersed to the extent that, by the beginning of the twenty-first century, a significant number of primary care trusts (PCTs), which were supposed to be the key vehicles for health improvement under the reorganisation of the NHS implemented by the new government, reported that they had no access at all to specialist health promotion staff. ${ }^{101}$

A succession of further Health Service reorganisations, particularly affecting PCTs, led to more fragmentation of the HPS workforce, which in any case had not really recovered from the introduction of the purchaser-provider split a decade earlier. ${ }^{102}$ This time, however, the background policy rhetoric excluded health promotion and reinforced the concept of 'public health'. The result was the further marginalisation of SHP and a strong sense that it had lost control over that part of the health improvement agenda about which it was supposed to be expert. In studies, HPSs spoke of the importance to them of the term 'health promotion': of how this identified particular kinds of practice, and how these had been lost among the other activities of the public health departments that they now worked in. ${ }^{103,104}$ To the extent that the HPS role was recognised at all, it was as some kind of loosely specified adjunct to 'public health'. SHP had become a specialised element within the larger public health workforce. ${ }^{105}$ Professionalisation had already faltered and failed; now too had the idea of health promotion as a specialism. The specialisation was public health, within which the knowledge, understanding and expertise that SHP had struggled to describe and develop might or might not be found.

\section{Why did Specialisation fail? Why did the Professionalisation Project Collapse?}

I began this paper with the claim that, at least with regard to some cases in the field of medicine and health care, a relationship exists between processes of specialisation and professionalisation. A group seeking to professionalise, to become a profession, must believe that it has particular knowledge and expertise in relation to a given domain. That is to say, it must believe that it is, or has the potential to become, a specialism. The group must therefore develop or enhance its specialism in order to promote claims to becoming a profession (claims to power and control over the domain concerned). In the most effective cases, presumably, the relationship between specialisation and professionalisation is a symbiotic one.

So the easy, but not very helpful, answer to the questions above is that SHP failed to professionalise because it failed to advance sufficiently as a specialism. The question then becomes: why did it fail to advance and develop as a specialism? I argue that my narrative has demonstrated three key closely connected difficulties impeding the development of health promotion as a specialism, a field to which HPSs could reasonably lay claim. First, there was the difficulty of the specialists agreeing what they should be doing and how they should be doing it. Second, there was the problem of them finding a place within the NHS to do their work. Third, there was the difficulty that another much more powerful group (medicine and its ancillary public health medicine) was staking claim to the domain.

\footnotetext{
${ }^{101}$ Department of Health, Shaping the Future of Public Health: Promoting Health in the NHS (London: Department of Health, 2005).

102 Judy White, What Future for Health Promotion? Report of a Workshop and Survey of Practitioners Working in Specialised Health Promotion in the North of England (Leeds: Centre for Health Promotion Research, 2009).

103 Caroline Coen and Jane Wills, 'Specialist Health Promotion as a Career Choice in Public Health', Journal of the Royal Society for the Promotion of Health, 127 (2007), 231-8.

${ }^{104}$ White, op. cit. (note 102).

105 Department of Health, op. cit. (note 101).
} 
Taking the first difficulty, throughout the period I have been considering, SHP suffered a profound crisis of identity. It was almost constantly asking itself (and having asked of it) questions about what it actually was and what it should be doing. An apparently clear and important global rhetoric (Lalonde, the Ottawa Charter and so on) seemed very hard to translate into local practice or even national recommendations for practice. If Ottawa talked about the need to change structures, the experience of most HPSs for most of the time was that they were engaged in the projects of individual behaviour change that government strategy during the period consistently identified as being the appropriate priority for health promotion. In effect, HPSs were being presented with two different possibilities for practice. One of these was officially sanctioned and the other provided a kind of rallying cry for the radical activists among their number. The consequences of this were that it divided SHP into the separate camps of those who were pragmatic about practice on the one hand, and those who in the various ways that I have described rejected pragmatism on the other. This division in turn made it hard to see what might constitute 'authentic' practice, the 'true' nature of health promotion. Under these conditions of division and dispute it is hard to see either how a specialism could be developed or, of course, a professionalisation project succeed.

One thing that might possibly have moved HPSs some way towards resolving the issue of what constituted 'authentic' practice was a clear answer to the question of what actually worked in terms of improving health. An answer might have encouraged HPSs to think in more unified ways about their practice. It might also have made policymakers consider (or possibly reconsider) the direction in which they were encouraging work to go (either confirming that direction or possibly changing it). Some answers were certainly found; for example, the understanding that efforts at individual behaviour change in the primary care context were to some extent effective but were also extremely costly. ${ }^{106}$ The problem was that the answers were very often equivocal. (It is difficult if not impossible to apply randomised controlled trials to health promotion simply because an intervention of this kind and its effects cannot be isolated; and therefore the relationship between intervention and effects is seldom if ever clear.) Moreover, simply because of the disputed nature of health promotion, research findings were often subject to ideological interpretation. ${ }^{107}$

Moving on to the second problem, that of finding a place within the NHS for HPSs to work, it seems reasonable to suppose that a specialism requires an acceptable and appropriate organisational place from which the putative specialist area can successfully develop. ${ }^{108}$ This was deeply difficult for SHP. The removal of HEOs from local government to the NHS in 1974 exposed them to what turned out to be the first of a series of almost continuous attempts to reorganise the service according to the requirements of its various political controllers. ${ }^{109}$ Historians of health and health care have pointed to the need for more analytical attention to be paid to the implications for the political economy

\footnotetext{
${ }^{106}$ Family Heart Study Group, 'Randomised Controlled Trial Evaluating Cardiovascular Screening and Intervention in General Practice: Principle Results of the British Family Heart Study', British Medical Journal, 308 (1994), 313-20; Imperial Cancer Research Fund Oxcheck Study Group, 'Effectiveness of Health Checks Conducted by Nurses in Primary care: Final Results of the Oxcheck Study Group', British Medical Journal, 310 (1995), 1099-1104.

107 Jackie Green and Keith Tones, Health Promotion: Planning and Strategies Second Edition (London: SAGE, 2010).

108 Coventry and Pickstone, op. cit. (note 20).

${ }^{109}$ Webster, op. cit. (note 37).
} 
of health that arose as a result of the 1974 reforms. ${ }^{110}$ SHP provides a clear example of the adverse effect of these reforms on the 'health economy', where this is understood in much wider terms than simply treatment and care. The problem was that those controlling the health economy were largely concerned simply about treatment and care, allowing little opportunity for the careful development of a specialism that fell outside of these areas.

The third and final difficulty was that of another, much more powerful group - medicine and its ancillary of public health medicine - staking claim to the domain of concern. The influence of medicine on health education and health promotion is quite clear within this narrative. The Cohen Committee, which essentially provided for the development of health education in the second half of the twentieth century, was formed of a medical majority. From the era of the $\mathrm{MOH}$ onwards, doctors most often managed those working in the field. ${ }^{111}$ The 'medical model' of individual behaviour change in relation to specific disease or disease risk also dominated approaches to health promotion, often to the distaste of HPSs. ${ }^{112}$ Descriptions of medicine's influence on health promotion, however, only go some way towards explaining the impact that it had on attempts by SHP to create a specialism.

Medical historians have argued that the emergence of specialisation in the broad field of medicine depends on a number of conditions, including confident technical development and an increasing public understanding of the area that is in the process of emerging as a specialism. ${ }^{113,114}$ Equally, it has been argued that the process is aided by a 'rational state', which supports the development of medical knowledge on which specialisation depends. Such support is founded on a belief that both knowledge and specialisation will be beneficial to the state's citizens. ${ }^{115}$

The long-standing dominance of medicine within the broad field of health is clear. ${ }^{116}$ If health education (and then health promotion) were to develop at all, they would need to do so in ways that somehow involved medical patronage. Medicine would need to accept the legitimacy of the putative specialism, both on its own terms and also on behalf of the public and policy interests that it thought itself to be representing. For this to happen, at the very least the conditions described above would need to be present.

I argue that they were not. Health education (and health promotion) knowledge grew from ideas emerging in the relatively new field of the social sciences. ${ }^{117}$ It is true that there were what might be thought of as 'technical developments' (in the form of, for example, the understanding and use of mass media). However, these were fragmentary and emanated from fields that were in themselves contested and viewed with suspicion by

\footnotetext{
${ }^{110}$ Coventry and Pickstone, op. cit. (note 20).

${ }^{111}$ HEOs were directly managed by MOHs in pre-1974 local authority arrangements. Post-1974, it is true that management arrangements varied between separate district health authorities, then trusts. However, many HPSs continued to be managed by medics in the form of Specialists in Community Medicine, and then Directors of Public Health. At any rate, the hand of medicine in management of the specialist occupation was never far away. See Sutherland, op. cit. (note 26); Kate Jezernik, Forced Marriages: Health Promotion and Public Health (unpublished MSc dissertation: University of London, 2003).

112 Rawson and Grigg, op. cit. (note 11).

113 Coventry and Pickstone, op. cit. (note 20).

114 Heggie, op. cit. (note 4).

115 Weisz, op. cit. (note 2).

116 Sarah Earle and Gayle Letherby (eds), The Sociology of Health Care (Basingstoke: Palgrave Macmillan, 2008).

${ }^{117}$ Robin Bunton and Gordon Macdonald, Health Promotion: Disciplines, Diversity and Developments Second Edition (London: Routledge, 2002).
} 
'objective science'. ${ }^{118}$ Public understanding of health education and health promotion was essentially mediated by medicine, which cast the 'health education facts' in a broad context of 'medical knowledge', suitably diluted for public consumption by medical diktat. ${ }^{119,120}$ Equally, 'rational policy making' in the field has often been founded on beliefs about the value of objective medical knowledge, scepticism as to the social science foundations of health promotion and the consequent view that, if it is to exist at all, it should do so as an adjunct of medicine. ${ }^{121}$ Essentially, medicine could see no reason why health promotion should exist as a specialism in the way that those working in SHP conceived it. (Although, as I have emphasised, exactly what this conception might be was far from clear and highly disputed among HPSs themselves.)

\section{Conclusion}

The professionalisation project of SHP failed because health promotion failed to advance as a specialism. It failed to advance because of internal dispute, lack of an adequate organisational place from which to develop and the much more powerful interests of medicine staking claim to the putative specialism's area. These three reasons for the failure of specialisation are closely connected and, taken together, demonstrate the importance of the narrative presented here.

It has been claimed with some reason that we are entering a new era in health policy and planning, an era in which traditional concern with treatment and care, while remaining important, will need to be seen in the context of much larger and ultimately significantly threatening problems. These include climate change, resource depletion and dealing with inequalities that exist both within and between states. ${ }^{122}$ In some ways, addressing these kinds of problems requires the sort of action proposed by the global strategies that have formed part of the narrative in this paper; for example, the Ottawa Charter. It is unlikely that the problems will be effectively addressed through an individual, disease prevention orientation.

Yet it is this orientation that has persisted through the recent history of SHP and eventually contributed to its decline and failure. A focus on the individual divided HPSs: it failed to give them a proper organisational place, and it was fundamental to medicine staking a successful claim to health promotion. The failure of SHP in effect demonstrates a failure in constructing alternative ways of thinking about health problems. Of course, HPSs were small in number, and even if successful in specialising and professionalising, would still have had to face enormous problems in conveying any kind of challenge to political and other orthodoxies. The point is that structures and contexts did not even allow them to begin. Yet if reorientation is required, as has been claimed, the kinds of alternatives posed

\footnotetext{
118 Peter Duncan, Critical Perspectives on Health (Basingstoke: Palgrave Macmillan, 2007).

119 See for example Farrant and Russell, op. cit. (note 71) for a revealing description of this process.

${ }^{120}$ Public understanding of health education/health promotion and their purposes is an important yet neglected issue. In terms of this account of a putative specialism attempting to professionalise, one thing it is possible to note is that HPSs may have been doing a disservice to themselves by more or less insisting that they only work with other professionals in a facilitating or advisory role. Such a position clearly would have made it difficult or impossible for the specialists to engage directly with the public on issues of understanding, related to both what health promotion actually was, and what they sought to do. Self-imposed exile from the public cannot help the processes of specialisation and professionalisation, if these things depend in part on public acceptance or at least acquiescence.

${ }^{121}$ K. Lucas and B. Lloyd, Health Promotion: Evidence and Experience (London: SAGE, 2005).

${ }^{122}$ Hanlon et al., op. cit. (note 9).
} 
by SHP have to be considered. Thus historical understanding of the failure and how it is related to conceptual, organisational and ideological difficulties might help in determining how the reorientation in health policy and planning that some insist is now required can be better achieved in the future.

With this in mind, what I began by claiming was an under-researched area is worthy of more extensive exploration than this paper by itself allows. Global comparison, understanding how other states might have coped (or otherwise) with the challenge of finding a place for the putative specialism of health promotion in their structures and contexts is one interesting possibility. Another is the deeper exploration of what has happened in the English context; moving beyond the policy and other texts that have been instrumental in the construction of this narrative and towards fieldwork that actually listens to the voices of those who experienced the failure of SHP. These are just two possible further research directions for an important and so-far neglected area, which if treated carefully has much to tell us about future possibilities for effective, appropriate and sustainable health policy and practice. 